\title{
Anúncios de negros escravizados nas páginas do jornal “Correio Paulistano" em 1854
}

\author{
Black slave ads in the pages of the newspaper "Correio Paulistano" in 1854
}

Beatriz Isabelly da Cruz Almeida, Priscila Lena Farias

história de São Paulo, negros, escravidão, anúncios de jornais

Esse artigo apresenta os resultados de uma pesquisa que busca compreender as questões raciais apresentadas nos anúncios de escravos publicados nas edições do jornal Correio Paulistano.

Comparando os anúncios de escravos com os demais anúncios publicados no jornal, buscou-se encontrar semelhanças e diferenças no uso de famílias tipográficas e na linguagem visual utilizada. Anúncios publicados nas edições de 1854, primeiro ano de publicação do jornal, foram analisados. Um número significativo de anúncios de fuga de escravos utilizando capitulares foi encontrado.

São Paulo's history, black people, slavery, newspaper's ads

This article presents the results of a research that seeks to understand the racial issues presented in the advertisements of slaves published in the editions of the newspaper Correio Paulistano. Comparing the slave ads with other ads, we sought to find similarities and differences in the use of typefaces and in the visual language employed. Ads published in the 1854 issues of the journal, the first year of its publication, have been analyzed. A significant number of slaves' escape announcements using drop caps were found.

\section{Introdução}

Esse artigo apresenta os resultados de uma pesquisa de iniciação científica, em andamento, que tem por objetivo principal analisar os elementos gráficos presentes nos anúncios de escravos nas edições do jornal Correio Paulistano, contribuindo para um melhor entendimento da situação racial paulistana na segunda metade do século XIX. Esta pesquisa faz parte do projeto de Memória (tipo)gráfica Paulistana, coordenado pela Prof. ${ }^{a}$ Dra. Priscila Farias no Laboratório de Pesquisa em Design Visual (LabVisual) da Faculdade de Arquitetura e Urbanismo da Universidade de São Paulo (FAU USP). Nesse projeto são estudados e discutidos diversos temas relacionados à história da tipografia na cidade de São Paulo, tais como: a tipografia no espaço urbano, o repertório tipográfico de antigas oficinas tipográficas, a presença de mulheres na prática da impressão etc. A questão da raça ainda não fora abordada, apesar de claramente presente nos jornais oitocentistas, onde a objetificação e o apagamento dos corpos negros permaneceram estampados. Curitiba | Brazil | 2021 
Um dos mais importantes jornais oitocentistas foi o Correio Paulistano. Lançado em junho de 1854, primeiro jornal diário paulista e terceiro no Brasil, teve como fundador o proprietário da Tipografia Imparcial, Joaquim Roberto de Azevedo Marques, e como primeiro redator Pedro Taques de Almeida Alvim. Segundo Cohn (2009), o periódico tem trajetória complexa. Nascido liberal, teria passado a adotar linha editorial conservadora ao final da década de 1860, tornando-se órgão do Partido Republicano Paulista (PRP) em 1873. Em 1874 teria adotado linha reformista, e, a partir de 1882, sob a direção de Antônio Prado, teria assumido a defesa do abolicionismo, e posteriormente a defesa da ordem republicana. Tornou-se novamente oligárquico e conservador a partir da Proclamação da República, em 1889. Por sua relevância, quantidade de edições, e, principalmente, por apresentar diversos anúncios relacionados a escravos, foi escolhido como foco de estudo. Um grande volume das edições deste jornal encontra-se digitalizado e disponível no portal da Hemeroteca Digital da Biblioteca Nacional (bndigital.bn.gov.br).

Através da análise do uso de fontes, clichês e vinhetas tipográficas em anúncios de escravos, busca-se entender como a cultura escravocrata paulistana se posicionava graficamente em meados do século XIX.

\section{Metodologia e desenvolvimento}

A pesquisa iniciou com leituras relacionadas à escravidão, à produção e circulação de anúncios comerciais e também à história da imprensa e da tipografia em São Paulo. Esse aprofundamento teórico forneceu dados históricos para contextualização das etapas posteriores, que envolveram seleção e coleta de imagens de anúncios, e, em um segundo momento, organização das imagens e análise dos dados.

\section{Levantamento bibliográfico, leituras e fichamentos}

Além de bibliografia básica contemplando questões relacionadas à história da tipografia no Brasil e na cidade de São Paulo (entre outros, FARIAS 2016 e 2019; FARIAS, ARAGÃO, e CUNHA LIMA 2012), foi necessário identificar e analisar outros textos relevantes para a compreensão da cultura racial paulistana. Estes textos foram encontrados nas referências bibliográficas de obras de autores como Schwarcz (1986), Azevedo (1987) e Nascimento (2019).

Foram realizados fichamentos de textos considerados relevantes, destacando-se as ideias mais importantes e compilando-as em forma de resumo segundo a ordem de seu aparecimento nos textos. Essas informações foram organizadas em arquivo de texto, juntamente com informações sobre autoria e título.

\section{Seleção e coleta de imagens de anúncios}

A seleção de imagens foi realizada a partir de consultas regulares ao acervo da Hemeroteca Digital da Biblioteca Nacional, a partir da primeira edição do jornal Correio Paulistano, publicada em junho de 1854. 
Por se tratar de um jornal diário e de longa duração, foram selecionadas para análise apenas as 20 primeiras e as 20 últimas edições do primeiro ano de publicação do jornal (1854). A quarta e última página de cada uma das edições selecionadas, contendo a seção de anúncios, foi examinada. Nos casos em que se verificou a existência de anúncios relacionados ao comércio de escravos, a página foi coletada e as imagens dos anúncios tratadas.

\section{Organização dos dados}

As imagens coletadas foram descritas e organizadas em uma planilha Excel (figura 1), destacando-se:

- Tipo de anúncio (compra, venda, fuga, leilão, ama de leite ou aluguel de escravos).

- Transcrição do texto do anúncio.

- Letras e imagens utilizadas no anúncio.

- Tamanho do anúncio (em linhas).

- Posição na seção de anúncios e destaque do anúncio estudado em relação ao resto da página.

Figura 1: Planilha utilizada para o registro e classificação dos anúncios

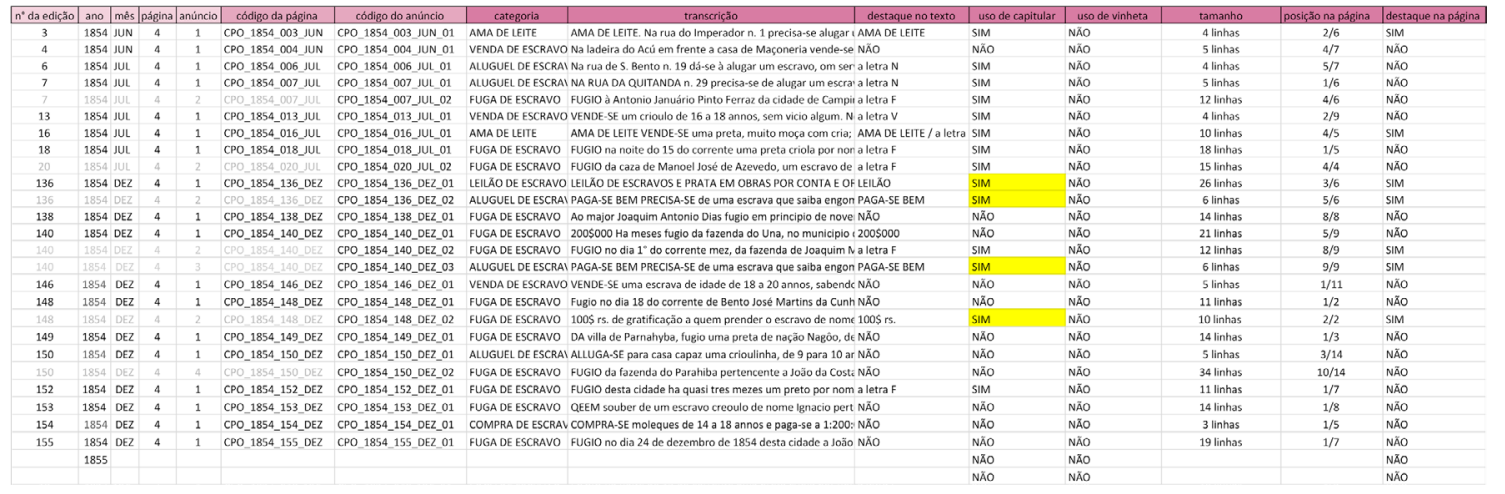

\section{Resultados}

Foram identificados ao menos seis tipos de anúncios de escravos nas edições consultadas do jornal Correio Paulistano, de 1854. Estes referem-se a diversas maneiras através das quais os escravos eram comercializados - aluguel, venda, compra, leilões - e também a fugas. Muitos deles contém descrições físicas dos escravos (figura 2). A maioria dos anúncios encontrados era de fuga de escravos, e foi publicada em dezembro (tabela 1). 
Figura 2: Exemplos de anúncios coletados: Compra, Aluguel, Leilão, Fuga, Ama de leite e Venda

COMPRA-SE moleques de 14 a 18 innos, e paga-se a $1: 200: 000$; nesla typographia se dirá quem compra.

5a aUGIO a Antonio Januario Pinto Ferraz da cidade de Campinas um mulato, de nome Antonio cujos signaes sũo os seguintes : rosto com signaes de bexigas e de sardas, altura regular, cabellos crespos ; lcvou bastante roupa fina.

Quem o aprehender ou d'elle der noticia cerla será bem gratificado, alem das despezas que fizer. Protesta-se igualmente com todo o rigor da lei contra quem o tiver acoutado.
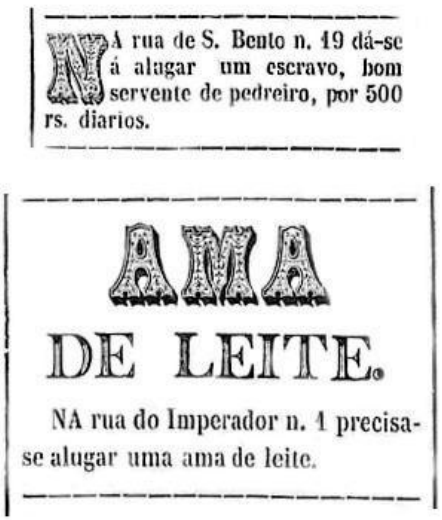

ENDE-SE um crioulo de 16 a 18 annos, sem vicio algum. Nesta typographia se dirá quem

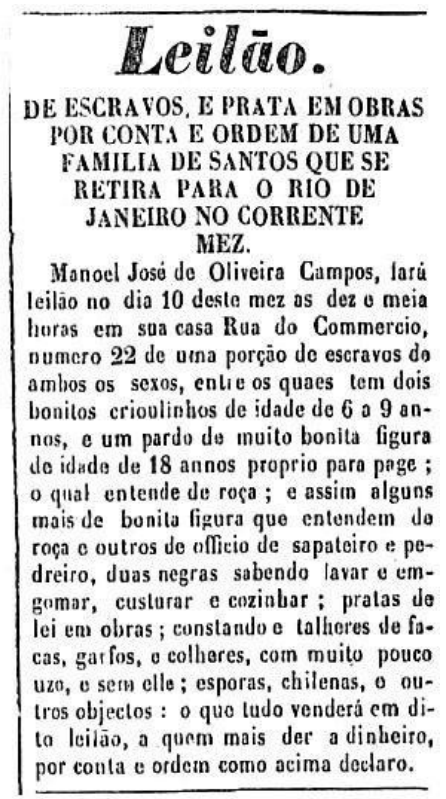

Tabela 1: Tipo e quantidade de anúncios encontrados nas edições do Correio Paulistano de 1854

\begin{tabular}{lccccccc}
\hline Mês & Aluguel & $\begin{array}{c}\text { Ama de } \\
\text { Leite }\end{array}$ & Compra & Fuga & Leilão & Venda & Total \\
\hline Junho & 0 & 1 & 0 & 0 & 0 & 1 & 2 \\
Julho & 2 & 1 & 0 & 3 & 0 & 1 & 7 \\
Dezembro & 3 & 0 & 1 & 10 & 1 & 1 & 16 \\
\hline Total & 5 & 2 & 1 & 13 & 1 & 3 & 25 \\
\hline
\end{tabular}

Das 40 edições analisadas, 21 possuíam anúncios relacionados a escravos. Foram identificados um total de 42 anúncios, sendo 25 sem repetição. O número máximo de anúncios em uma mesma edição foi 4 (edição 150 do mês de dezembro). Observou-se que a categoria mais comum foi a de fuga de escravos, representando 13 dos 25 itens, e as menos comuns as de compra e leilão, que aparecem apenas uma vez cada uma, sempre em dezembro.

Em todos os anúncios de ama de leite, e no de leilão de escravos, foi observado o uso de letras iniciais em destaque. Dos 6 dos 13 anúncios de fuga analisados, apresentaram uso de capitulares rebaixadas, quase sempre a letra $F$ (figura 2). Dos 13 anúncios que utilizam capitulares, sete foram destaque na página do jornal, isto é, foram os únicos anúncios que apresentaram letras com tamanho diferenciado (figura 3). O número médio de linhas observado nos anúncios mais longos, de fuga e leilão foi de 15 linhas - 10 linhas no mais curto e 26 linhas no mais longo. Os anúncios de aluguel, compra e venda de escravos contém no máximo 6 linhas. Não foram encontrados anúncios de escravos com ornamentos ou vinhetas. 
Figura 3: Página com anúncio de Ama de Leite em destaque, com letras grandes e ornamentadas.

4

CORneio paUListano.

flor nenlium caso tem feito das que Ilıe lem sido applicadas, com prejuizo do publico que anda por ali ás marralas pelo escuro, chemando it ponlo que um pobre viajor vindo the Santos, andou a noite inteir perdido pela ciulade sem achar sahida, não podendo por isso seguir a sua viagem para Jundiahy, o que sij pe demanhia quando o Sr. A pollo mandou accender o seu grande lampiäo. Uw dos que tem soffrido.

\section{$\longrightarrow$ Dopes-}

Sr. Nedictor do Correio Prulistano.

- Digne-se V. S. par a luz do meio dis us poucess reflexōes que passamos a dirigir-lhe acerta de dois objectos bern distinctas.

Em Indos es paizes civilisados a illuminação das roas, mormento nas capitaes o cidades populosas, tem sido sempre reconhlucida como uma das primeiras necessidades ; ebtre nós paréen, a illunuinacăo da capital, parcee que é mais uma pençâo ao contractador, un meio de vil

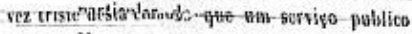
Nos arralaaldes da cidade janıis se acendem os lampioes, e no interior $\mathrm{b}$ um formalidade que dara poucas horas : demadrugada, oh! que bellas madrugadas paro os presos quo fogem da cadeia ! c um inferno do Dante, escuridāo cuanple$\mathrm{ta}, \mathrm{c}$ a algumas distancias como diz Milton, uma pequena laz quanto baste par mostrar o horror das Ireyas. Pelianos a S. Ex- o Sr, presidente que ollie para esta lastima.

Outro pedido ou reparo, é para o esta do do soffrimento em que so achia os empregados da repartiçẫo do sello, collıcados entre uma clóica o a estrumeira dos cavallos e bestas que de continuo fazem sua residentia no curredor contiguo : isto quanda nào firsso un relaixamento inqualificavel de lal reparlição, devera merecer a atlengào do guverno, cumo medida hygienica.

X. P. $T, O$.

\section{PACtos maversos.}

Como baviames annunciado em o 1. desta folha, S. Ex o Sr. Dr Jusino nat vespera de deisar a administrakajo des. ta provincia fundou a irmandadu de $\mathrm{S}$. Jorgư nesta capital.
Ilojo danıos an prablito a eleição da NA loja que foi de Joaquim José ueza de que naquella data ainda uão ti- Alres dos Santos, presentemente loge uhamos conhecimesto, o que fícon com- de louça, continual-se a vender por prosta dos seguintes Srs. :

Provedor - Brigadeiro Rafocl Tobiss de Aguiar.

Sccretario.-Major Cypriano Roelsa Liana.

Thesaureiro.-Coroncl Ignacio Jose de Araujo.

Procurador, - Tenenle-Coronul Joaquim ue Souza Guimarû̀s Canancáa. Irmazos de mera,-Tenente-Coronel Joảo Nunes Ramalluo, Jaảo Corlos do Baurñann, Claudio Josó Pereira, o Amador Redrigues Jordĩo.

-

A tenanhã na igreja do S. Francisco ba festa do Espirito Suato, de que é Imperador o Sr. capitao Segesmunto Honorio de Limo.

\section{ANNUNCIOS.}

J. JACQUES OSWALD, não fícou sorpreienditio pelo anuuncio publicado ne . Correio Paulistanoo de hontem, pelo Sr. Luis Perigault, por quanto este mesmo Sr.t. teve a coragem de lazer varios aununcios convidando pessoas para o Tivoly da Luz, depois de denunciado pelo an nunciante, em estado de fillimento. 0 annunciante está dando andamento ao seu processo de fallimento, e breve provarí que no Brasil la leis que nào permiltem que qualquer bancarroteiro fratudulento sacrilique a forImua altheia.

\section{J. J. Oswald, 国算凰 DE LEITE.}

NA rua do Imperador n. 1 precise se alugar uma ama de leite.

GLSTAYO IIELHOLD, prolesso de piano, laz publico que, concerta afina pianos com perfeição. Pode ser procurado na rua da Santa caza
n. 10 . preços commodos. Na mesma caza

A5 MOVIMENTO DO POR- t5
TO DE SANTOS.

DE 18 A 23 DE JUNHO DE 1854 . ENtradas.

$$
\text { Dia } 19 .
$$

Rio de Jaxzizo, vapoúr nac. Itambé, 80 lons. carga, varios generos, MI. Joaquim Pereira Nunes Franco, propr. Luciano Leite Rilecira, consig. Jose Maria Largocha.

- vapớr, "nac., Uniđ̃o 82 tons, carga varies generos, MI. T. Luiz da Rueho Fraga, propr. C'. Macale \& Campos.

Cunsig Bernardino Ferreira da Silya, Dia 20.

-vapor nac. Princesa Loopoldina, 120 tons. carga varios generos, M. Antonio Franciseo Aleixo dos Sanlos, propr Rieardo Pinto Rilieiro do Moura. Dia 21.

- vapor de guerra Paraense, ao serviço do governo, trazendo a seu bordo o Exin. Presidente desta provincia. Par dia 22. carga 38 r alq. de farinha, 100 ditos de Teij., 12 barric de farin. 2 saceas de uro Carreirio, propr. Oliveira Rocho \& Sobr', consig. José Baptista Leal.

Bio DE Jaxeitto, brigue hambergue O'ra, 269 lons., em lastro, M. N. J. Richilsco, propr. Kalkmana, eonsig. Backlieuse \& Irms.

- patacloo nacionat 23. em lostro, M. Anlonio Baptista de Oliveira, propr. José Dias do Souza, consig. Ferreira Nitto \& $C^{8}$.

Esle patacho veio concluir sen earregamento para Porto Alegre.

Hanteungo, bia 24 . Valdemar, earga, fazendas, consignatarios, Theodor Wille \& Ca',

Dia 25

$$
\text { Dia } 25 .
$$

Rio de Jaserao, vapor bac. Fltuminense.

\section{EXPEDIENTE.}

Podemos assegurar ao comnercio desta provincia, que seremos sollicitos e attentos para este ramo de industria. Possuimos um optimo correspondente em Santos, que nos porá ao facto de tudo o que occorrer e interessar ao corpo do commercio.

S. PAULO. - 1854. - TyPograph AIPARCIAL de Harques \& Irmäo Rua Noeza de $S$. José $n, 47$ : la superior chá da India. Olireira Rocha \& Solrinho, coosiz.

Parakagé liate nac. S. Joẫo, 17 lons., gomma, 26 alq. de millio, M. J. Pe-

\section{Discussão}

Os anúncios examinados, apesar de não terem sido elaborados com o propósito de ser um registro histórico e tipográfico de sua época, comunicam as nuances do pensamento racial do século XIX. É notável, por exemplo, o modo como a linguagem utilizada deixa subentendida a diferença entre "nós" (anunciantes e leitores) e "eles" (sujeitos anunciados). Os escravos eram 
sempre colocados no lugar do outro. Em um anúncio com o texto "Vende-se moleques" fica implícito que os tais meninos são negros, já que crianças brancas não seriam comercializadas.

As caracterizações dos escravos fugidos são outro aspecto relevante. Altura, tom de pele, qualquer tipo de cicatriz ou "defeito" chamativo, modo de falar, jeito de andar e eventualmente sua nação de origem foram utilizados para descrever as pessoas negras, de modo bastante detalhado, na maioria dos anúncios examinados.

Capitulares rebaixadas e fontes com desenhos incomuns foram usadas para destacar os anúncios, revelando o empenho e a urgência dos senhores de escravos para recuperar suas "posses", oferecendo recompensas.

\section{Conclusão}

Em 1854, os anúncios de escravos publicados no Correio Paulistano relataram, principalmente, fugas, utilizando anúncios extensos contendo descrições físicas e trejeitos dos escravizados. Apesar do uso frequente de capitulares, estes anúncios não ocupavam posição de destaque na página. A população escrava era retratada por seus senhores, e pelos redatores do Correio Paulistano, como propriedade. Estes sujeitos eram animalizados, tratados como se não tivessem família, origem, ou nome próprio.

Nos anúncios examinados não foram encontradas, como se esperava, vinhetas para representar os escravos, tais como aquelas com imagens de negros levando trouxas de roupa já identificadas em catálogos tipográficos brasileiros (Cunha Lima, Aragão e Farias 2013). De acordo com Cohn (2019), o Correio Paulistano apresentou uma alternância entre posicionamentos liberais e conservadores. Análises futuras devem permitir observar essa mudança, e devem ajudar a melhor compreender as escolhas linguísticas e gráficas adotadas pelo periódico para se referir à população negra, contribuindo para um entendimento mais amplo do papel da tipografia na produção e circulação de anúncios relacionados à escravidão em São Paulo; e para esclarecer as consequências da publicação de anúncios como estes para as relações raciais estabelecidas entre membros da sociedade paulistana.

\section{Agradecimento}

A pesquisa foi realizada com apoio de bolsas PIBIC e PQ do CNPq.

\section{Referências}

Azevedo, C. M. (1987). Onda Negra Medo Branco. O negro no imaginário das elites do século XIX. Rio de Janeiro: Paz e Terra.

Cohn, A. (2009). Correio Paulistano. In: Acervo do CPDOC FGV - Centro de Pesquisa e Documentação de História Contemporânea do Brasil / Dicionário Histórico-Biográfico Brasileiro - DHBB. Disponível em <http://www.fgv.br/cpdoc/acervo/dicionarios/verbetetematico/correio-paulistano> 
Cunha Lima, E. L. ; Aragão, I. R. ; Farias, P. L. (2013). Describing movable type specimens: a contribution to Brazilian (tipo)graphic memory. In: Fadel, L. M.; Spinillo, C. G.; Moura, M.; Triska, R.. (Org.). Selected Readings of the 5th Information Design International Conference: research and practice. Florianópolis: Sociedade Brasileira de Design da Informação, 2013, pp. 233-249.

Farias, P. (2016). Estudos sobre tipografia: letras, memória gráfica e paisagens tipográfica. Tese de Livre-Docência, FAU USP.

_ (2019). Visualizing data on graphic memory research. In: Selected Readings of the 8th Information Design International Conference: Memories. São Paulo: Blucher.

Farias, P. L.; Aragão I. R. \& Cunha Lima E. L. (2012). Unraveling aspects of Brazilian design history through the study of 19 th century almanacs and type specimens. In: Conference Proceedings: DRS 2012. Bangkok: Chulalongkorn University.

Nascimento, D. (2019). O Prefeito Antônio Prado e a população negra da cidade de São Paulo (1899 - 1911). In: Anais XVIII ENANPUR. Disponível

em:<http://anpur.org.br/xviiienanpur/anaisadmin/capapdf.php?reqid=632>. Acesso em: 5 de outubro de 2020.

Schwarcz, L. M. (1986). Imagens de negros: a imprensa paulistana no final do seculo XIX: e como atraves de suas paginas, os brancos viam os negros. Dissertação de mestrado, Universidade Estadual de Campinas, Instituto de Filosofia e Ciências Humanas.

\section{Sobre as autoras}

Beatriz Isabelly da Cruz Almeida, bolsista de Iniciação Científica, USP, Brasil

<trisalmeida@usp.br>

Priscila Lena Farias, Professora Associada, USP, Brasil

<prifarias@usp.br> 